\title{
Comparison of Effects of Intravenous Etomidate and Propofol during Induction of Anaesthesia for Electroconvulsive Therapy
}

\author{
Lavan Sagar Pragada ${ }^{1}$, Vivek Chakole², Bhakti Patil ${ }^{3}$
}

\begin{abstract}
${ }^{1}$ Department of Anaesthesiology, Jawaharlal Nehru Medical College, Datta Meghe Institute of Medical Sciences (DMIMS) \& Acharya Vinoba Bhave Rural Hospital, Sawangi (Meghe), Wardha, Maharashtra, India.

2Department of Anaesthesiology, Jawaharlal Nehru Medical College, Datta Meghe Institute of Medical Sciences (DMIMS) \& Acharya Vinoba Bhave Rural Hospital, Sawangi (Meghe), Wardha, Maharashtra, India.

${ }^{3}$ Department of Anaesthesiology, Jawaharlal Nehru Medical College, Datta Meghe Institute of Medical Sciences (DMIMS) \& Acharya Vinoba Bhave Rural Hospital, Sawangi (Meghe), Wardha, Maharashtra, India.
\end{abstract}

\section{ABSTRACT}

\section{BACKGROUND}

Electroconvulsive therapy (ECT) is a standard procedure in the modern psychiatric armamentarium. It involves, application of electric stimulus for a brief time in psychiatric patients to induce generalized seizure. ECT is utilized for treating various severe, treatment-resistant or refractory psychiatric disorders, schizophrenia and major depressive disorder (MDD). During ECT, severe disturbances can be noted in the cerebrovascular and cardiovascular system. Various anaesthetic drugs used in modified ECT can prevent these disturbances. We wanted to compare induction time, alteration of hemodynamics, seizure duration, and recovery time by using intravenous etomidate and intravenous propofol for induction of anaesthesia in modified electroconvulsive therapy.

\section{METHODS}

Sixty patients were included in this prospective and comparative study. Patients of age group of 18-60 years of either sex, who had been posted for ECT therapy were randomly divided into two groups. Group E received Inj. Etomidate at $0.2 \mathrm{mg} / \mathrm{Kg} \mathrm{IV}$ and Group P received Inj. Propofol $1 \%$ at $1.5 \mathrm{mg} / \mathrm{Kg}$ for induction of anaesthesia. Patients were monitored for various haemodynamic parameters such as heart rate, blood pressure at basal, after induction, and $1 \mathrm{~min}, 2 \mathrm{~min}, 3 \mathrm{~min}, 5 \mathrm{~min}, 10 \mathrm{~min}$ and 20 min following ECT. Induction time, seizure duration, quality of anaesthesia and recovery time from anaesthesia were also noted.

\section{RESULTS}

Induction of anaesthesia is faster with propofol $(40.30 \pm 3.65 \mathrm{sec})$ than with etomidate $(48.63 \pm 3.29 \mathrm{sec})$. Longer seizure duration was found with etomidate $(58.90 \pm 11.91 \mathrm{sec})$ induction in comparison to propofol $(22.16 \pm 5.48 \mathrm{sec})$ induction. Propofol group had more stable hemodynamic parameters compared to etomidate group following ECT. Propofol group $(7 \pm 1.43 \mathrm{~min})$ achieved consciousness earlier than those of etomidate group $(8.60 \pm 1.16 \mathrm{~min})$ following induction.

\section{CONCLUSIONS}

Propofol had the advantage of smooth induction, stable hemodynamic parameters, and rapid recovery as compared to etomidate. However, it was associated with shorter seizure duration. Etomidate had longer seizure duration which results in better clinical outcomes over propofol. However, it was associated with greater incidence of myoclonic jerks during induction.

\section{KEY WORDS}

Electro-Convulsive Therapy, Etomidate, Propofol
Corresponding Author:

Dr. Lavan Sagar Pragada,

Department of Anaesthesiology,

JNMC, Sawangi (Wardha-442001),

Maharashtra, India.

E-mail:dr.lavansagar@gmail.com

DOI: $10.14260 / j e m d s / 2020 / 263$

Financial or Other Competing Interests: None.

How to Cite This Article:

Pragada LS, Chakole V, Patil B. Comparison of effects of intravenous etomidate and propofol during induction of anaesthesia for electroconvulsive therapy. J. Evolution Med. Dent. Sci. 2020;9(14):1215-1219, $10.14260 /$ jemds $/ 2020 / 263$

Submission 29-01-2020, Peer Review 14-03-2020, Acceptance 20-03-2020, Published 06-04-2020.

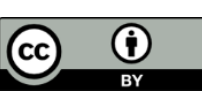




\section{BACKGROUND}

Electroconvulsive therapy (ECT) involves, application of electric stimulus for a brief time in anaesthetized patients to induce generalized seizure. Electroconvulsive therapy is the most effective biological procedure utilized for treating various severe, treatment-resistant or refractory psychiatric disorders, schizophrenia and major depressive disorder (MDD) (1).

The efficacy of electroconvulsive therapy is dependent on the induced seizure duration.(2,3). EEG (electroencephalograph) seizure activity is said to have optimal efficacy of treating depression, when it lasts for 25 to 50 seconds. Least favourable response to ECT occur when patients experience seizure duration of $<15$ seconds or $>120$ seconds. (4)

During ECT, severe disturbances can be noted in the cardiovascular system. These changes include, transient hypertension and changes in the heart rate (HR).(5) Also, following ECT, cerebral blood flow and intracranial pressure markedly increases.(6) ECT induce hemodynamic changes which can result in myocardial ischemia and infarction.(7) Also, cerebrovascular changes following ECT can result in cortical blindness, intracerebral haemorrhages and transient neurologic ischemic deficits.(8,9) Unmodified direct ECT associated with physical and psychological trauma in the past, has now been modified with anaesthesia.(2,10) Various anaesthetic drugs used in modified ECT can alter these cardiovascular changes and use of muscle relaxants can reduce the violent muscular contractions during the convulsions.(5)

Etomidate contains a carboxylated imidazole ring. The imidazole ring in etomidate, gives the properties of lipid solubility at physiological pH and water solubility in acidic solutions. Therefore, its preparation is dissolved in a lipid emulsion or propylene glycol for injection.(11) Etomidate acts by inhibiting the reticular activating system and mimics action of GABA (gamma-aminobutyric acid) inhibition. The $\mathrm{R}$ $(+)$ isomer of Etomidate particularly appears to bind specifically to a subunit of the $G_{A B A}$ receptor, thus increasing the affinity for inhibitory neurotransmitter i.e. GABA. $(12,13)$

Propofol structure includes phenol ring substituted with two groups of isopropyl (2, 6-diisopropylphenol) is primarily a hypnotic agent and has rapid onset of action for induction of anaesthesia. Propofol allosterically increases affinity of binding GABA to $\mathrm{GABA}_{\mathrm{A}}$ receptor. This receptor is coupled to a chloride $\left(\mathrm{Cl}^{-}\right)$channel and activation of the receptor results in hyperpolarization of the nerve membrane.(14) Propofol binds to multiple ion channels and receptors. The $\alpha 2$ adrenoceptor system indirectly causes sedation due to propofol.(15) Propofol also causes inhibition of NMDA (Nmethyl D-aspartate) receptor, which is a subtype of glutamate receptor. This inhibition is due to activation of sodium $\left(\mathrm{Na}^{+}\right)$ channels; which may contribute to the CNS effects of propofol.

In our present study, we compare the effects of injection etomidate and propofol, used for intravenous induction of anaesthesia in modified Electroconvulsive therapy with respect to induction time, quality of induction of anaesthesia, hemodynamic stability, seizure duration and recovery profile.

\section{METHODS}

This prospective, comparative study was carried out at the Department of Anaesthesiology, Jawaharlal Nehru Medical College, Datta Meghe Institute of Medical Sciences (DMIMS) and Acharya Vinoba Bhave Rural Hospital, Sawangi (Meghe), Wardha, Maharashtra from October 2017 to September 2019.

\section{Sample Size Calculation-}

$n=\frac{(\mathrm{Z} \alpha+\mathrm{Z} \beta)^{2} \cdot 2 \cdot(\mathrm{S})^{2}}{\mathrm{~d}^{2}}$

Z $\alpha$ : Two tailed significance level 5\% $=1.96$

$Z \beta$ : Power of study $90 \%=0.94$

$(\mathrm{Z} \alpha+\mathrm{Z} \beta) 2=(1.96+0.94) 2=8.4$

$\mathrm{S}=16.4(\mathrm{~S}=$ standard deviation of SBP, $\mathrm{d}=$ mean difference of SBP)

$\mathrm{d}=15.5$

$n=\frac{8.4 \times 2 \times(16.4 \times 16.4)}{(15.5 \times 15.5)}$

$=18.8$

The sample size obtained was 19 for each group which was rounded up to 30 for each group. So final sample size estimated was 60. Reference article for sample size calculation is taken from the study done by Mir et al.

This prospective, randomized comparative study carried out after obtaining Institutional Ethics Committee approval. Written informed consent from sixty patients of American Society of Anesthesiologists (ASA) ${ }^{(16)}$ class I and II, aged 1860 years, scheduled for ECT therapy, included in this study. Patients with severe systemic disorder like IDDM, uncontrolled hypertension, kidney or liver disease, severe respiratory disorder, seizure disorder, coronary artery disease or recent history of MI, concomitant use of TCA, SSRI, MAO inhibitors or opioids, patients with known hypersensitivity or allergy to drugs to be used, anticipated difficult airway, body weight $>100 \mathrm{~kg}$ or obese and pregnant or breast feeding females and in patients in whom seizures failed to occur during ECT were excluded from the study.

Patients included in the study were randomized by computer operated random number table. Each study group consists of 30 patients.

Group E- Received Inj. Etomidate at $0.2 \mathrm{mg} / \mathrm{Kg}$ for induction of anaesthesia.

Group P - Received Inj. Propofol $1 \%$ at $1.5 \mathrm{mg} / \mathrm{Kg}$ for induction of anaesthesia.

All the patients planned for electroconvulsive therapy were assessed one day prior to the procedure. Patients of both the study groups were kept nil per oral of at least 6 hours prior to the procedure. Upon arrival of patient into the procedure room, multi parameter monitor was attached to patient for continuous monitoring of Heart Rate, electrocardiogram, non-invasive blood pressure and oxygen saturation $\left(\mathrm{SpO}_{2}\right)$. Baseline values of vital parameters were noted. An IV line was established with 20G IV cannula. Inj. glycopyrrolate $0.2 \mathrm{mg}$ IV as premedication is given to all the patients. Preoxygenation is done for 3 minutes with $100 \%$ 
oxygen. Induction of General anaesthesia was done with IV anesthetic agent, inj. etomidate $(0.2 \mathrm{mg} / \mathrm{Kg})$ or inj. propofol $(1.5 \mathrm{mg} / \mathrm{Kg})$ as per the group allocated, till loss of eyelid reflexes. To ensure accurate registration of the motor seizure, the blood pressure cuff of the upper limb was inflated 50 $\mathrm{mmHg}$ above the systolic blood pressure (SBP) to isolate the circulation. Following induction, IV succinylcholine 0.5 $\mathrm{mg} / \mathrm{Kg}$ was administered for neuromuscular relaxation and to avoid convulsion induced complications among all patients. Once the fasciculations subsided and following adequate neuromuscular relaxation, a bite block of appropriate size was inserted to prevent tongue bite. A brief pulse stimulus for about 1-3 seconds, frequency of $60-90 \mathrm{~Hz}$ and pulse width of 1 was given to produce seizures. Seizure duration was monitored by isolated limb method. Subsequently, ventilation was assisted with face mask in all patients with $100 \%$ oxygen at a rate of $12-16$ breaths/min until return of spontaneous breathing and clinical recovery of patient from anaesthesia. Patients were monitored for various hemodynamic parameters such as heart rate, systolic and diastolic blood pressure (SBP and DBP) and oxygen saturation $\left(\mathrm{SpO}_{2}\right)$. Baseline values noted before induction and changes noted after induction at $1 \mathrm{~min}, 2 \mathrm{~min}, 3 \mathrm{~min}, 5 \mathrm{~min}$, $10 \mathrm{~min}$ and $20 \mathrm{~min}$ following ECT. Time taken for recovery from anaesthesia was recorded with respect to time taken to achieve consciousness, obey commands, orientation and for ability to sit unaided. The collected data were analyzed statistically using one-way ANOVA test. The values were considered significant when the P-value is $<0.05$.

\section{Statistical Analysis}

Statistical analysis was done using descriptive and analytical statistics. The chi square test was used to check differences in proportions. Continuous variables are expressed as mean and standard deviation. The normality of continuous data was analysed by the Shapiro-Wilk test. As the data followed normal distribution, parametric test (t-test) was used to analyse the data. The independent sample $t$ - test was used to check mean difference. The level of significance was kept at $\mathrm{p}<0.05$.

\section{RESULTS}

All the patients in both groups were comparable with respect to demographic profile which includes age, body weight statistically showed no significant difference. Results of our study showed that the induction was rapid with propofol as compared to etomidate, which was statistically significant ( $p$ $<0.001$ ). Induction time with propofol was $40.3 \pm 3.65$ seconds and that for etomidate was $48.63 \pm 3.29$ seconds (table-1)

Mean duration of seizure activity (table-1) between both the groups were comparable and found significantly longer in etomidate group $(58.9 \pm 11.91 \mathrm{sec})$ as compared to propofol group $(22.16 \pm 5.48 \mathrm{sec})$. The mean heart rate (HR) between the two groups at various time intervals was compared. It was found that there was NO statistically significant difference in mean heart rate between the two groups at baseline $(p=0.301), 1$ minute $(p=0.063), 10$ minute $(p=0.362)$ and at 20 minutes ( $\mathrm{p}=0.859)$. Heart Rate (table-2) were comparable in both the group and statistically significant at time intervals $2 \mathrm{~min}, 3 \mathrm{~min}$ and at $5 \mathrm{~min}(\mathrm{p}<0.001$, at all-time intervals) following ECT with propofol the HR change was $15-17$ beats/min above the baseline values in the first $2 \mathrm{~min}$, whereas with etomidate group HR varied from 35 to 38 beats/min above baseline values. Systolic blood pressure at baseline was similar in both the groups $(p=0.153)$. Our study results showed that increase in the systolic blood pressure (SBP) following ECT, with propofol, was comparatively less than that with etomidate (table-3). Change in the mean SBP, in propofol group was 20-24 mmHg above the baseline value in the first $2 \mathrm{~min}$, while with etomidate, mean SBP raised by $38-42 \mathrm{mmHg}$ above the baseline value in the first $2 \mathrm{~min}$ following ECT. After 2 min of ECT, SBP of both groups gradually declined to reach baseline values. SBP in propofol group reached the baseline values after $10 \mathrm{~min}$ following ECT, but in etomidate group it is beyond 20 min post ECT.

Diastolic blood pressure (table-4) at baseline was similar in both the groups $(\mathrm{p}=0.618)$. Results showed statistically significant difference in mean diastolic blood pressure at various other time intervals $(\mathrm{p}<0.05)$. Propofol caused a little increase in mean diastolic blood pressure (DBP), around 10$13 \mathrm{mmHg}$ above the baseline value in the first $2 \mathrm{~min}$ following ECT. With etomidate, the mean DBP increased by 15-17 mmHg above the baseline value in first 2 min post ECT was observed. After 2 min of ECT, DBP of both groups gradually declined to reach baseline values. DBP in both the group reached close to baseline values by $10 \mathrm{~min}$ following ECT.

The mean arterial pressure (table-5) between the two groups at various time intervals was compared. At baseline the mean arterial pressure was similar in both the groups $(p=0.250)$. The mean arterial pressure (MAP) values were less raised in propofol in comparison to etomidate group post ECT. After $2 \mathrm{~min}$ of ECT, MAP of both groups gradually declined to reach baseline values. MAP in propofol group reached the baseline values after $10 \mathrm{~min}$ following ECT, but in etomidate group it is beyond 20 min post ECT. Although both the study drugs showed a very short time for recovery (table6), patients of propofol group achieved consciousness earlier than those of etomidate group following induction $(7 \pm 1.43$ min and $8.6+1.16$ min respectively with $\mathrm{p}<0.001$ ), but other parameters of recovery such as obeying commands, orientation and able to sit unaided were not significant between two groups.

\begin{tabular}{|c|c|c|c|c|c|}
\hline \multirow[t]{2}{*}{ Variable } & \multicolumn{2}{|c|}{ Group E $(n=30)$} & \multicolumn{2}{|c|}{ Group P $(n=30)$} & \multirow[t]{2}{*}{ P-Value } \\
\hline & Mean & S.D. & Mean & S.D. & \\
\hline Induction & 48.63 & 3.29 & 40.30 & 3.65 & $<0.001, \mathrm{~S}$ \\
\hline Seizure & 58.90 & 11.91 & 22.16 & 5.48 & $<0.001, \mathrm{~S}$ \\
\hline \multicolumn{6}{|c|}{$\begin{array}{l}\text { Table 1. Comparison of Induction and Seizure Time } \\
\text { (Secs) between the Two Groups }\end{array}$} \\
\hline
\end{tabular}

\begin{tabular}{|c|c|c|c|c|c|}
\hline \multirow[t]{2}{*}{ HR (bpm) } & \multicolumn{2}{|c|}{ Group E $(n=30)$} & \multicolumn{2}{|c|}{ Group P $(n=30)$} & \multirow[t]{2}{*}{ P-Value } \\
\hline & Mean & S.D. & Mean & S.D. & \\
\hline Baseline & 76.80 & 7.42 & 78.86 & 7.90 & $0.301, \mathrm{NS}$ \\
\hline $1 \mathrm{~min}$ & 96.90 & 7.57 & 92.96 & 8.49 & 0.063 , NS \\
\hline $2 \min$ & 112.86 & 6.77 & 94.93 & 7.79 & $<0.001, S$ \\
\hline $3 \min$ & 109.96 & 6.40 & 92.03 & 7.77 & $<0.001, S$ \\
\hline $5 \mathrm{~min}$ & 102.46 & 6.59 & 84.43 & 7.78 & $<0.001, S$ \\
\hline $10 \mathrm{~min}$ & 80.43 & 5.79 & 78.83 & 7.57 & 0.362 , NS \\
\hline $20 \mathrm{~min}$ & 76.76 & 5.40 & 77.06 & 7.49 & $0.859, \mathrm{NS}$ \\
\hline \multicolumn{6}{|c|}{$\begin{array}{l}\text { Table 2. Comparison of Mean Heart Rate between the Two } \\
\text { Groups at Various Time Intervals }\end{array}$} \\
\hline
\end{tabular}




\begin{tabular}{|cccccc|}
\hline SBP (mmHg) & \multicolumn{2}{c}{ Group E (n=30) } & \multicolumn{2}{c|}{ Group P (n=30) } & P-Value \\
& Mean & S.D. & Mean & S.D. & \\
Baseline & 122.73 & 6.37 & 119.86 & 8.76 & 0.153, NS \\
$1 \mathrm{~min}$ & 157.00 & 5.62 & 139.00 & 7.38 & $<0.001, \mathrm{~S}$ \\
$2 \mathrm{~min}$ & 162.80 & 5.39 & 141.40 & 7.02 & $<0.001, \mathrm{~S}$ \\
$3 \mathrm{~min}$ & 151.60 & 5.39 & 131.06 & 7.09 & $<0.001, \mathrm{~S}$ \\
$5 \mathrm{~min}$ & 143.90 & 6.55 & 126.30 & 6.99 & $<0.001, \mathrm{~S}$ \\
$10 \mathrm{~min}$ & 133.10 & 6.07 & 121.70 & 7.96 & $<0.001, \mathrm{~S}$ \\
$20 \mathrm{~min}$ & 127.60 & 6.15 & 119.60 & 8.04 & $<0.001, \mathrm{~S}$ \\
\hline Table 3. Comparison of Mean Systolic Blood Pressure between \\
the Two Groups at Various Time Intervals \\
\hline SBP = Systolic blood pressure, n= number; S.D. = standard deviation, E= Etomidate; \\
P= Propofol, S= Significant; NS= Non- Significant \\
\hline \multicolumn{7}{c}{}
\end{tabular}

\begin{tabular}{|c|c|c|c|c|c|}
\hline \multirow[t]{2}{*}{ DBP (mmHg) } & \multicolumn{2}{|c|}{ Group E $(n=30)$} & \multicolumn{2}{|c|}{ Group P $(n=30)$} & \multirow[t]{2}{*}{ P-Value } \\
\hline & Mean & S.D. & Mean & S.D. & \\
\hline Baseline & 76.80 & 8.68 & 75.76 & 7.22 & $0.618 \mathrm{NS}$ \\
\hline $1 \mathrm{~min}$ & 93.03 & 8.33 & 84.16 & 6.96 & $<0.001, \mathrm{~S}$ \\
\hline $2 \min$ & 92.80 & 8.51 & 87.96 & 6.59 & $0.017, \mathrm{~S}$ \\
\hline $3 \mathrm{~min}$ & 88.60 & 8.80 & 79.26 & 6.18 & $<0.001, \mathrm{~S}$ \\
\hline $5 \mathrm{~min}$ & 80.60 & 7.44 & 77.03 & 6.10 & $0.047, \mathrm{~S}$ \\
\hline $10 \mathrm{~min}$ & 77.80 & 6.60 & 74.33 & 5.53 & $0.032, \mathrm{~S}$ \\
\hline $20 \mathrm{~min}$ & 75.66 & 6.51 & 71.26 & 5.49 & $0.006, \mathrm{~S}$ \\
\hline \multicolumn{6}{|c|}{$\begin{array}{c}\text { Table 4. Comparison of Mean Diastolic Blood Pressure between } \\
\text { the Two Groups at Various Time Intervals }\end{array}$} \\
\hline
\end{tabular}

\begin{tabular}{|c|c|c|c|c|c|}
\hline \multirow[t]{2}{*}{ MAP(mmHg) } & \multicolumn{2}{|c|}{ Group E $(n=30)$} & \multicolumn{2}{|c|}{ Group P $(n=30)$} & \multirow[t]{2}{*}{ P-Value } \\
\hline & Mean & S.D. & Mean & S.D. & \\
\hline Baseline & 92.10 & 7.14 & 89.96 & 7.09 & $0.250 \mathrm{NS}$ \\
\hline $1 \mathrm{~min}$ & 114.36 & 5.76 & 102.53 & 5.76 & $<0.001, S$ \\
\hline $2 \min$ & 116.10 & 5.95 & 105.73 & 5.31 & $<0.001, S$ \\
\hline $3 \min$ & 109.56 & 5.93 & 96.46 & 5.28 & $<0.001, S$ \\
\hline $5 \mathrm{~min}$ & 101.66 & 5.08 & 93.53 & 5.09 & $<0.001, S$ \\
\hline $10 \mathrm{~min}$ & 96.26 & 4.71 & 90.06 & 5.13 & $<0.001, S$ \\
\hline $20 \mathrm{~min}$ & 93.00 & 4.87 & 87.43 & 5.03 & $<0.001, S$ \\
\hline \multicolumn{6}{|c|}{$\begin{array}{l}\text { Table 5. Comparison of Mean Arterial Pressure between the } \\
\text { Two Groups at Various Time Intervals }\end{array}$} \\
\hline
\end{tabular}

\begin{tabular}{|c|c|c|c|c|c|}
\hline Recovery & \multicolumn{2}{|c|}{ Group E $(n=30)$} & \multicolumn{2}{|c|}{ Group P $(n=30)$} & \multirow[t]{2}{*}{ P-Value } \\
\hline Time (secs) & Mean & S.D. & Mean & S.D. & \\
\hline Consciousness & 8.60 & 1.16 & 7.00 & 1.43 & $<0.001$, S \\
\hline Obey Command & 9.03 & 1.15 & 8.70 & 1.62 & $0.364, \mathrm{NS}$ \\
\hline Oriented & 11.30 & 1.36 & 10.43 & 1.95 & 0.052 , NS \\
\hline Sit Unaided & 14.23 & 2.02 & 14.83 & 2.92 & $0.360, \mathrm{NS}$ \\
\hline \multicolumn{6}{|c|}{ Table 6. Comparison of Recovery Time ( $\mathrm{min}$ ) between the Two Groups } \\
\hline \multicolumn{6}{|c|}{$\begin{array}{l}\mathrm{n}=\text { number; S.D. }=\text { standard deviation. } \mathrm{E}=\text { Etomidate; } \mathrm{P}=\text { Propofol. } \mathrm{S}=\text { Significant; } \\
\mathrm{NS}=\text { Non- Significant. } \text { secs }=\text { seconds }\end{array}$} \\
\hline
\end{tabular}

\section{DISCUSSION}

An ideal induction agent for ECT should ensure rapid induction of unconsciousness, stable haemodynamics, minimal effects over seizure duration or amplitude, rapid recovery of consciousness, and should be inexpensive.(17) The demographic profile of age, weight and gender were studied. Our study results were concurrent to many studies, which showed no significant variability to demographic parameters for the action of the induction agent. Our study is concurrent to studies done by Mir et al.(18) who studied the effect of three induction agents thiopentone, Propofol and etomidate in different age groups and weight and their results were comparable but statistically not significant.

Induction was rapid with propofol as compared to etomidate $(\mathrm{p}<0.001)$, This was in concurrent to the study conducted by Bergen JM et al (19) who studied etomidate for rapid sequence induction. In our study, mean duration of seizure activity was found significantly longer in etomidate group ( $\mathrm{p}<0.001)$. Our results were comparable to the study conducted by Avramov et al(20) who compared effects of methohexitate, propofol and etomidate in ECT. Their study results showed the durations of EEG and motor seizures were longest after etomidate and shortest after propofol.

All the hemodynamic parameters (HR, SBP, DBP and MAP) were less raised in Group P in comparison to Group E post ECT at all the study time intervals. In our study propofol seemed to be superior to etomidate in attenuating the cardiovascular stress response to ECT with minimal hemodynamic changes. Similar, results were noted in a study conducted by Gazdag et al(21) who compared propofol and etomidate for ECT in patients with schizophrenia. Their results showed, when using propofol, the increase in MAP was significantly lower than when etomidate was used $(8.1 \pm$ $10.2 \mathrm{~mm} \mathrm{Hg}, 18.3 \pm 11.2 \mathrm{~mm} \mathrm{Hg}, \mathrm{P}=0.001$ ). Zgola et al ${ }^{(22)}$ also found similar results with propofol and etomidate in patients undergoing implantable cardioverter-defibrillator testing. Their study results showed that propofol significantly decreased the values of all measured hemodynamic parameters.

In our study patients of propofol group achieved consciousness earlier than those of etomidate group following induction $(\mathrm{p}<0.001)$. our study results correlate with the study conducted by Rosa et al,(23) who studied recovery after ECT among three study groups (propofol, etomidate and thiopental). In their study, recovery time for propofol was $7.4 \pm 1.9 \mathrm{~min}$, whereas for etomidate it was 10.7 $\pm 3.6 \mathrm{~min}$, thus the results showed that recovery time for propofol is less than etomidate in patients undergoing ECT.

\section{CONCLUSIONS}

For induction of ECT, etomidate and propofol had their own advantages and disadvantages with regard to individual study parameters. Propofol had the advantage of smooth induction, stable hemodynamic parameters, and rapid recovery as compared to etomidate. However it was associated with shorter seizure duration. Etomidate had longer seizure duration which results in better clinical outcomes over propofol. However it has less stable hemodynamic control and longer induction time.

\section{Limitations}

Our study included patients of only ASA class I and II. Hence effects of propofol and etomidate for ECT among elder patients and those having associated cardiovascular comorbidities are yet to be studied. Since our sample size includes only 60 patients, of 30 in each study group, results obtained cannot be generalized for entire population. Thus, further studies should be designed and conducted with larger study groups including patients with comorbidities and also to use combination of drugs for optimal effects.

Recommendations

From our study we found that in patients with ASA grade I and II, intravenous induction of anaesthesia with inj. propofol $(1.5 \mathrm{mg} / \mathrm{Kg}$ ) for electroconvulsive therapy is safe, effective, has smoother induction, better hemodynamic profile and has faster recovery from anaesthesia following ECT. Whereas, inj. Etomidate $(0.2 \mathrm{mg} / \mathrm{Kg})$ IV when used for induction of anaesthesia in ECT has shown to have longer duration of 
seizures and recovery profile nearly similar to propofol induction but has poor haemodynamic stability following ECT.

\section{REFERENCES}

[1] Leiknes KA, Jarosh-von Schweder L, Høie B. Contemporary use and practice of electroconvulsive therapy worldwide. Brain Behav 2012;2(3):283-344.

[2] Thompson JW, Weiner RD, Myers CP. Use of ECT in the United States in 1975, 1980, and 1986. Am J Psychiatry 1994;151(11):1657-61.

[3] American Psychiatric Association. The practice of electroconvulsive therapy: recommendations for treatment, training, and privileging: a task force report of the American Psychiatric Association. American Psychiatric Pub 2008.

[4] Sackeim HA, Devanand DP, Prudic J. Stimulus intensity, seizure threshold, and seizure duration: impact on the efficacy and safety of electroconvulsive therapy. Psychiatr Clin North Am 1991;14(4):803-43.

[5] Painuly N, Chakrabarti S. Combined use of electroconvulsive therapy and antipsychotics in schizophrenia: the Indian evidence. A review and a metaanalysis. J ECT 2006;22(1):59-66.

[6] Saito S, Miyoshi S, Yoshikawa D, et al. Regional cerebral oxygen saturation during electroconvulsive therapy: monitoring by near-infrared spectrophotometry. Anesth Analg 1996;83(4):726-30.

[7] López-Gómez D, Sánchez-Corral MA, Cobo JV, et al. Myocardial infarction after electroconvulsive therapy. Rev Esp Cardiol 1999;52(7):536.

[8] Rikher KV, Johnson R, Kamal M. Cortical blindness after electroconvulsive therapy. J Am Board Fam Med 1997;10(2):141-3.

[9] Weisberg LA, Elliott D, Mielke D. Intracerebral hemorrhage following electroconvulsive therapy. Neurology 1991;41(11):1849.

[10] Ekinci M, Hsu JJ, Bruck M, et al. Diazepam as an anticonvulsant agent in ECT. Am J Psychiatry 1964;120:9034.
[11] Doenicke A, Roizen MF, Hoernecke R, et al. Haemolysis after etomidate: comparison of propylene glycol and lipid formulations. Br J Anaesth 1997;79(3):386-8.

[12] Evans RH, Hill RG. GABA-mimetic action of etomidate. Experientia 1978;34(10):1325-7.

[13] Guitchounts G, Stewart DS, Forman SA. Two etomidate sites in $\alpha 1 \beta 2 \gamma 2 \gamma$-aminobutyric acid type A receptors contribute equally and non-cooperatively to modulation of channel gating. Anesthesiology 2012;116(6):1235-44.

[14] Krasowski MD, Koltchine VV, Rick CE, et al. Propofol and other intravenous anesthetics have sites of action on the $\gamma$-Aminobutyric Acid type A receptor distinct from that for isoflurane. Mol Pharmacol 1998;53(3):530-8.

[15] Kushikata $T$, Hirota $K$, Yoshida $H$, et al. Alpha-2 adrenoceptor activity affects propofol-induced sleep time. Anesth Analg 2002;94(5):1201-6.

[16] Haynes SR, Lawler PGP. An assessment of the consistency of ASA physical status classification allocation. Anaesthesia 1995;50(3):195-9.

[17] Folk JW, Kellner $\mathrm{CH}$, Beale MD, et al. Anesthesia for electroconvulsive therapy: a review. J ECT 2000;16(2):157-70.

[18] Mir AH, Shah NF, Din MU, et al. Effectiveness of sodium thiopentone, propofol, and etomidate as an ideal intravenous anesthetic agent for modified electroconvulsive therapy. Saudi J Anaesth 2017;11(1):26-31.

[19] Bergen JM, Smith DC. A review of etomidate for rapid sequence intubation in the emergency department. J Emerg Med 1997;15(2):221-30.

[20] Avramov MN, Husain MM, White PF. The comparative effects of methohexital, propofol, and etomidate for electroconvulsive therapy. Anesth Analg 1995;81(3):596-602.

[21] Gazdag G, Kocsis N, Tolna J, et al. Etomidate versus propofol for electroconvulsive therapy in patients with schizophrenia. J ECT. 2004 Dec;20(4):225-9.

[22] Zgoła K, Kułakowski P, Czepiel A, et al. Haemodynamic effects of etomidate, propofol and electrical shock in patients undergoing implantable cardioverterdefibrillator testing. Kardiol Pol 2014;72(8):707-15.

[23] Rosa MA, Rosa MO, Belegarde IMT, et al. Recovery after ECT: comparison of propofol, etomidate and thiopental. Braz J Psychiatry 2008;30(2):149-51. 